\title{
Nonlinear Response Amplification Mechanisms for Low Doses of Natural Product Nanomedicines: Dynamical Interactions with the Recipient Complex Adaptive System
}

\author{
Iris R Bell1,2, Barbara Sarter ${ }^{3}$, Mary Koithan ${ }^{2}$, Leanna J Standish ${ }^{4}$, Prasanta Banerji' and Pratip Banerji ${ }^{5}$
}

${ }^{1}$ Department of Family and Community Medicine, The University of Arizona College of Medicine, USA

${ }^{2}$ College of Nursing, The University of Arizona, Tucson, AZ, USA

${ }^{3} \mathrm{Hahn}$ School of Nursing and Health Sciences, University of San Diego, San Diego, California, USA

${ }^{4}$ Bastyr University, Kenmore, WA, USA

${ }^{5} \mathrm{PBH}$ Research Foundation, Kolkata, India

\begin{abstract}
The purpose of the present paper is (a) to outline the self-organized, complex adaptive network nature of the organism as recipient of nanomedicines; (b) to propose several nonlinear endogenous amplification processes by which pulsed low doses of traditional, homeopathically-manufactured natural product nanomedicines may stimulate a return toward healthier function; and (c) to discuss their potential relevance to novel, but safer than conventional dosing strategies for contemporary nanomedicines. Homeopathy is an over 200 -year-old system of complementary and alternative medicine (CAM) that uses low doses of natural plant-, mineral-, and animal-sourced nanomedicines. Homeopathic manufacturing is "green", with mechanical grinding in lactose and agitation in ethanol-water as primary reagents. Agitation within glass containers at room temperature may also contribute nanosilica and nanosilicon as drug delivery vehicles and biological amplifiers. The medicine selection is matched to the recipient organism's systemic patterns of dysfunction and pulsed in the timing of the discrete doses. Endogenous amplification processes within the recipient organism may involve hormesis, time-dependent sensitization, and/or stochastic resonance. Effects are adaptive and systemically diffuse, i.e., causally indirect, rather than pharmacological and local, i.e., direct. All of these nonlinear response processes require interaction of the nanoparticle (NP) dose with the organism as a complex adaptive system. The pulsed NP dose serves as a low intensity salient danger signal for the organism to make network-wide adaptive changes that can lead to healing. The historically safe therapeutic approach of homeopathic nanomedicine dosing avoids risks of high, continuous doses and cumulative toxicity that contemporary nanomedicine researchers are now trying to solve while using NPs as if they were conventional bulk drugs. Integrating the insights, technical procedures, and clinical dosing approaches from modern and homeopathic nanomedicine could lead to major advances in the field for more effective and safer translational applications.
\end{abstract}

Keywords: Nanomedicine; Homeopathy; Nanoparticles; Hormesis; Stochastic resonance; Nonlinear dynamical systems; Complex adaptive systems

\section{Introduction}

The purpose of the present paper is (a) to outline the self-organized, complex adaptive network nature of the organism as recipient of nanomedicines; (b) to propose several nonlinear amplification processes by which pulsed low doses of traditional, homeopathicallymanufactured natural product nanomedicines may stimulate a return toward healthier function; and (c) to discuss their potential relevance to novel, but safer than conventional, dosing strategies for contemporary nanomedicines. Homeopathy is an over 200-year-old system of complementary and alternative medicine (CAM) that uses low doses of natural plant, mineral, and animal sourced nanomedicines. The medicine selection is matched to the recipient organism's systemic patterns of dysfunction, prepared in a "green" manner and pulsed in timing of the discrete doses [1,2]. Effects are adaptive and systemically diffuse, i.e., indirect causality, rather than pharmacological and local, i.e., direct causality.

Convergent basic science studies reveal the presence of mechanically-generated source material [3-5] and silica/silicon nanoparticles (NPs) in homeopathically-prepared medicines [4,69]. Nanobubbles made during the manufacturing process may also contribute to the final product $[8,10,11]$, which retains physicochemical properties of the original source material [12]. The evidence further suggests the presence of a polydisperse population of the source
NPs in homeopathic medicines [3]. NP concentrations are low, but measurable [3]. Like modern manufactured NPs [13], homeopathicallymanufactured medicines in solution also can exhibit aging effects $[9,14]$. These nanomedicines are delivered either in ethanolic liquids or sprayed and dried onto lactose or lactose/sucrose pellets for oral administration.

Homeopathic manufacturing materials and methods are inherently "green" $[15,16]$. Previous papers have addressed the striking similarities between modern top-down mechanical attrition procedures for making nanoparticles (NPs) [17] and historical homeopathic medicine manufacturing methods and materials [15,18-21]. These similarities include mechanically grinding source materials in lactose for hours and repeatedly agitating ethanol-water solutions containing the source

*Corresponding author: Iris R Bell, MD PhD, Department of Family and Community Medicine, The University of Arizona, College of Medicine, $1450 \mathrm{~N}$ Cherry Avenue, MS 245052, Tucson, AZ 85719, USA, Tel: 520-906-6767, Fax: 520-749-4509; E-mail: ibell@email.arizona.edu

Received July 10, 2013; Accepted July 28, 2013; Published July 30, 2013

Citation: Bell IR, Sarter B, Koithan M, Standish LJ, Banerji P, et al. (2013) Nonlinear Response Amplification Mechanisms for Low Doses of Natural Produc Nanomedicines: Dynamical Interactions with the Recipient Complex Adaptive System. J Nanomed Nanotechol 4: 179. doi:10.4172/2157-7439.1000179

Copyright: (c) 2013 Bell IR, et al. This is an open-access article distributed under the terms of the Creative Commons Attribution License, which permits unrestricted use, distribution, and reproduction in any medium, provided the original author and source are credited. 
Citation: Bell IR, Sarter B, Koithan M, Standish LJ, Banerji P, et al. (2013) Nonlinear Response Amplification Mechanisms for Low Doses of Natural Product Nanomedicines: Dynamical Interactions with the Recipient Complex Adaptive System. J Nanomed Nanotechol 4: 179. doi:10.4172/2157-7439.1000179

materials within glass containers at room temperature. Lactose may serve as a reducing, capping, and coating agent to modify and deliver homeopathically-made NPs [11,22-26].

Multiple laboratories have demonstrated release of nanosilica and silicon from the inside walls of glassware from agitation of liquid solutions [6-9,27-29]. Mechanical agitation also disperses larger structures into small nanoparticles [30-32]. Ethanol concentrations modify the size and shape of any resultant nanosilica [33]. Nanosilica and nanosilicon, when present from agitating the liquid medicines in glassware, would add (a) biological amplification and adjuvant effects [34,35] and (b) the possibility of serving as drug delivery vehicles [36,37] for homeopathically-manufactured natural source nanomedicines. Plants can coat the surface of such nanostructures [38] and minerals can serve as dopants to modify nanosilica/silicon properties [39]. Thus, surface-modified nanosilica/silicon could convey unique amplified plant- or mineral-derived information into cells, just as plant-synthesized gold nanoparticles can do [40].

The manufacturing methods encompass not only top-down mechanical methods, but potentially also bottom-up plant extract-based biosynthesis [40] and self-assembly of silica and silicon nanoparticles [41-44]. The serial "dilution" process of homeopathic manufacturing apparently removes bulk form materials from the agitated solutions, but ends up transferring the source nanoparticles from one preparation step to the next [11]. The final product is then delivered for oral administration either in ethanolic solutions or sprayed and dried onto lactose or lactose-sucrose pellets.

The specific ways in which homeopaths make and use their natural product nanomedicines are often overlooked in discussions of this field. It is essential to take a closer look at this aspect of homeopathic clinical theory and practice. The resultant insights may open new directions for how to use modern nanomedicines more safely and for greater effect.

\section{Dosing Nanoparticles for Safety: Low Pulsed Doses}

An emerging concern and challenge for the field of modern nanomedicine is clinical safety [45]. NPs are typically biologically super-potent forms of their source material [46]. Therapeutic dose ranges are lower than for bulk forms of the same medicines or herbs [4750]. In addition, nano-forms can also lower the dose at which toxicity can occur, thereby necessitating use of even lower doses for therapy. In some organisms, NP concentrations are as low as 1 nanomolar can still exert toxic effects $[45,51,52]$. Accumulation of toxic levels in vivo is a significant concern. Nanoscale agents acquire properties that are dependent not only upon material composition and dose, but also nanoparticle sizes, shapes, and surface chemistries [22,23,40,53-56].

Yet, properly-prescribed homeopathic nanomedicines have a strong 200 -year safety record in real-world use $[1,57,58]$. Homeopathic practice theory offers specific, practical strategies for choosing and dosing nanomedicines to avoid the risks of toxic NP effects. The core concept is to use the NPs not as pharmacological ligands for specific local cell receptors responsible for specific symptoms, but rather as low dose, pulsed discrete danger signals to mobilize the biological adaptation networks of the whole organism [21]. The treatment goal is to stimulate endogenous plasticity via self-amplifying functional networked changes across the organism as a whole, rather than to suppress expression of specific symptoms $[59,60]$. If they occur, the majority of "side effects" in homeopathy are early transient worsening of pre-existing symptoms, prior to evolution of improvements $[1,61]$.

Low dose stimulation of biological adaptation networks provides an explanatory mechanism for why sublingual, olfactory or even topical administration can produce far-reaching changes in biological networks [62-64]. Homeopathic medicines have traditionally been administered sublingually. These routes of administration are very accessible for NPs $[46,65]$. NP stimulation of multi-system networks exerted by ultra low NP doses administered orally would be predicted to have widespread and rapid effects on multi-system hierarchies of the nested and interactive systems that make up the living organism [60].

The homeopathically-inspired dosing strategies require a shift in mindset away from using nanomedicines in the same ways that conventional medicine uses bulk form drugs. The homeopathic approach takes advantage of the (a) organism-wide network integration of any living system as a complex adaptive system (CAS) with nonlinear dynamics; and (b) endogenous self-amplifying processes in which a complex adaptive system can engage to respond to the signal qualities of salient low level external threats. These processes include hormesis, time-dependent sensitization, and stochastic resonance. As noted above, the therapeutic goal is to induce adaptive and diffuse changes via cascades of events over the stress response pathways rather than just symptom-inhibitory local effects at specific receptors. Consistent with the inherent nature of cause-effect in complex systems $[66,67]$, the quality of the organism's response to a dose is indirect rather than direct and nonlinear rather than linear in causality.

The salience derives from the quality of the signal to herald a potential danger or threat to survival for the individual organism. Such a stimulus, stressor or signal delivered to an already-diseased organism perturbs or disrupts ongoing disease dynamics and functional network organization of the system $[68,69]$. The disruption leads to transient wider fluctuations of bidirectional change for a period of time prior to re-stabilization [70-72] (Figure 1). Shaping the overall direction of the dynamics of change toward lasting health is the process and goal of treatment.

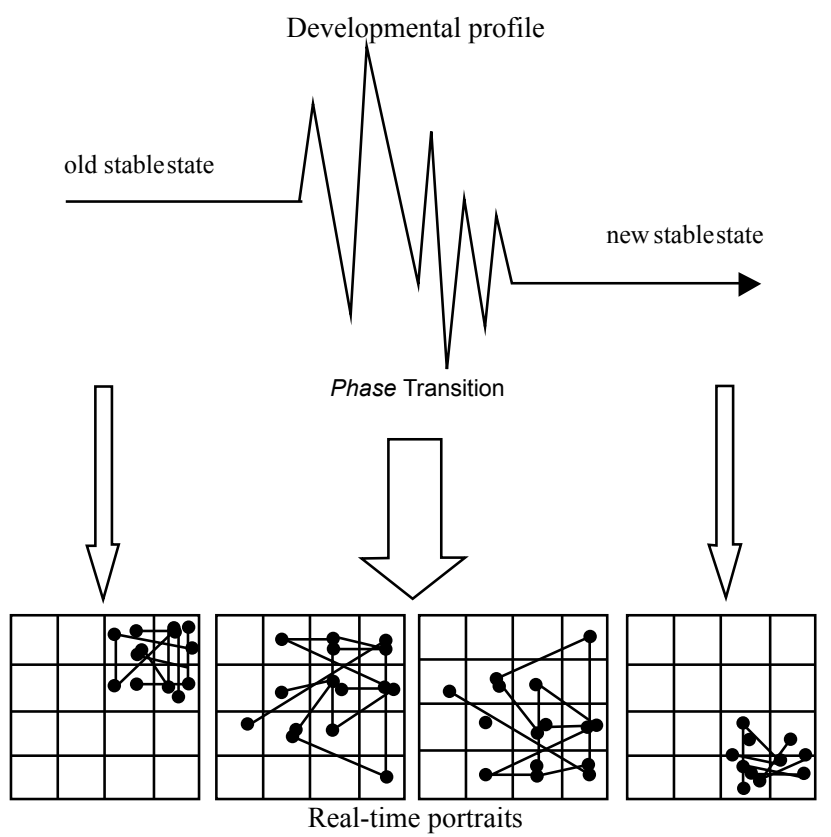

Figure 1: Perturbation of existing system dynamics by a developmental event or exogenous stressor. After perturbation occurs, the phase transitions involves bidirectional nonlinear excursions in the dynamics until the system restabilizes into a new functional pattern [70]. 
Citation: Bell IR, Sarter B, Koithan M, Standish LJ, Banerji P, et al. (2013) Nonlinear Response Amplification Mechanisms for Low Doses of Natural Product Nanomedicines: Dynamical Interactions with the Recipient Complex Adaptive System. J Nanomed Nanotechol 4: 179. doi:10.4172/2157-7439.1000179

Homeopathic dosing stops once improvement begins. The homeopathic clinical decision to give a subsequent dose occurs when the patient's overall symptom picture of dysfunctions is clear-cut and rises above day-to-day background fluctuations. The multiple changes that follow a single dose can evolve across the organism over a period of minutes to hours (acute conditions) to months to years (chronic conditions) in homeopathy. The evolution of changes across the organism would reflect the complex interconnected nature of the person as a biological network $[21,59,60]$.

One previous clinical trial documented oscillatory, sinusoidal response curves for several different outcomes over time to a verum homeopathically-prepared medicine compared with placebo [73]. When clinical improvement does occur, it can be reversed by overly frequent repetition of the homeopathic nanomedicine doses. Timing of repetitions can be more important than quantity of a given low dose in homeopathic treatment. Dosing a healthy organism pushes the system in the direction of disease (Table 1) [74]. Homeopathic medicine practices can provide insights into how best to dose and time NP therapies.

\section{Recipient Organisms as Self-Organized Complex Adaptive Networks}

In living systems, amplification processes go far beyond the enhanced bioavailability and biological potency of the nanomaterials themselves. The history and state of the recipient organism at the time it encounters NPs has an impact on the effects. Individual differences among organisms lead to divergent outcomes upon interaction with NPs [51]. Living systems such as human beings, animals, and plants are Complex Adaptive Systems (CAS) [62-64,75]. A CAS is a system or indivisible collection of multiple interconnected, interdependent, interactive parts embedded within a larger environment. A defining feature of CAS is their dynamic nature and capacity to adapt and evolve with changes in the environment [71]. Resilience in the face of environmental change is the hallmark of a successful CAS. They also possess other important characteristics.

First, biological processes take place at the nanoscale. Therefore, NPs intended for therapeutic applications often have unique capabilities for targeting specific cells, crossing membranes to enter cells more effectively than bulk form materials, and exerting effects for longer periods of time per dose. NP-based vaccines also provide indications of markedly enhanced adjuvant capacity for immune activation, thereby reducing the antigen doses required to evoke a vigorous response in the overall organism $[48,76]$. NPs from silica can mobilize inflammasome proteins inside a cell $[35,77,78]$. In turn, inflammasome mobilization leads to cytokine activation. Some NPs can also induce exosome release from cells $[79,80]$. Recent studies indicate that exosomes serve as cellto-cell signaling mediators [79,81-84].

Amplification of effects can readily occur in mobilizing cascades of events in the immune system, which would in turn send signaling mediators such as cytokines to the brain and other stress response pathways of the body. The brain per se is particularly capable of monitoring ongoing biological "noise" and sensory information for weak but relevant signals from internal and external stimuli and generating a large response when indicated. Thus, there are several interacting biological pathways in the neuro-immune network alone that can ultimately initiate robust biological adaptations much larger in magnitude than the original stimulus $[85,86]$. Immune and nervous system amplification is only one interconnected biological stress response pathway by which NPs could trigger changes in an organism as a whole.

Second, living systems are self-organized, complex adaptive systems (CAS) or networks with nonlinear dynamics and emergent properties that are not predicted by understanding the properties of their component parts $[60,87,88]$. NPs can both readily translocate around the organism and set cascades of biological signaling into motion, e.g., via activating exosome release $[80,89]$, inflammasome proteins and cytokines [65,77], and epigenetic modulation [90,91]. As a result, nano-drugs and natural products can elicit changes in cells and distant parts of an organism not obvious from a bulk medicine focus on only local inhibitory effects for specific symptoms [69]. These concepts imply the importance of the salience of an NP as a potential danger signal, or therapeutic stimulus, for the organism as a whole, especially at low doses [21,92].

Complexity in the nonlinear dynamics and functional organization of an intact cell or organism involves multiple interdependent and interactive functional relationships that can lead to indirect effects throughout the larger system $[68,69,93,94]$. The magnitude of those effects is nonlinear, i.e., it can be disportionately larger than the magnitude of the original stimulus [62-64]. As in any complex system, such effects occur distant in time and space from the original interface with NPs [95]. Within homeopathic practice theory, recovery of health proceeds down the body, from internal organs out toward the skin, and in reverse order of original appearance in time of the symptoms [60]. Such 200-year-old medical observations may help translate nanomedicine more efficiently into clinical practice.

\section{Endogenous Amplification Phenomena in Complex Adaptive Systems}

If a nanomedicine is correctly chosen and dosed to stimulate amplified responses and cross-adaptation, the resultant changes in the organism can even evolve into a recovery from a pre-existing disease over time. Such a process is a key principle in homeopathic practice theory [1]. Endogenous amplification in a complex adaptive system is inherently nonlinear [60]. That is, (a) the size of the response is disproportionate to the size of the input; (b) the direction of responses can be bidirectional or even oscillatory in nature [71]; (c) the location of the changes can be distant from the original site of the stimulus

\begin{tabular}{|l|l|}
\hline $\begin{array}{l}\text { Timing of Homeopathic Medicine Dose Relative to Experimentally-Induced } \\
\text { Injury }\end{array}$ & $\begin{array}{l}\text { Impact after } \mathbf{1} \text { hour on Injury-Related Edema Compared with Saline Control } \\
\text { Treatment }\end{array}$ \\
\hline 60 minutes before injury induction & $+14.6 \%^{*}$ \\
\hline Simultaneously with injury induction & $+3.57 \%$ \\
\hline 30 minutes after injury induction & $-13.63 \%^{* *}$ \\
\hline
\end{tabular}

30 minutes after injury induction

${ }^{*} p<0.05$

${ }^{* *} p<0.01$

Note: Experimental acute injury = carrageenan-induced paw edema. Verum medicine and saline control treatments were also given by injection

Table 1: Timing of intervention interacts with host state: bidirectional effects of a combination mineral homeopathic medicine dose relative to time of treatment versus time of experimental injury in an animal model of paw edema ( $\mathrm{N}=307$ rats). Data from first hour post-dose, after Figure 1, Bertani et al. [74]. 
Citation: Bell IR, Sarter B, Koithan M, Standish LJ, Banerji P, et al. (2013) Nonlinear Response Amplification Mechanisms for Low Doses of Natural Product Nanomedicines: Dynamical Interactions with the Recipient Complex Adaptive System. J Nanomed Nanotechol 4: 179. doi:10.4172/2157-7439.1000179

administration $[66,95,96]$. The discrete nanomedicine dose constitutes the pulsed input signal. The result is resistance or cross-resistance (adaptation or cross-adaptation) to same or similar biological stressor or injury, whether they already have occurred or might occur at higher intensities in the future [97-101].

The purpose of homeopathic treatment is not to force a specific change in a single target tissue with continuous dosing, in the manner of a conventional bulk form drug. Instead, the intent is to stimulate a cascade of multiple systemic adaptations around the network, all set into motion by the original salient stimulus of a discrete low dose of specific NPs [21]. The signal properties of the dose indicate a potential danger or threat that the treatment agent would pose for the whole organism at higher dose. The organism then takes its cue and makes functional biological changes across its networks to resist such current or future dangers $[18,21,68]$. That is, the organism adapts itself to perceived exogenous changes in order to maximize its fitness for survival in its "new" environmental context or landscape [102].

High doses of a toxic or dangerous agent, including many nanoparticles, can damage the organism or even cause death $[45,97]$. However, the direction of change from adaptation to a low dose that the organism can survive instead enhances resistance against the adverse effects of the same agent [97,98,103-105]. Furthermore, such beneficial changes can modify responses to not only the same, but also a cross-adapted agent or stressor. If the higher intensity past stressors have already done damage by causing maladaptive dynamical changes [106], i.e., disease, then the low dose treatment agent cross-adapted to the effects of those stressors could initiate a reversal of direction in the system dynamics [21].

For treatment of disease with this dosing strategy, the nanomedicine must be cross-adapted, cross-sensitized, and/or crossresistant in its effects to pre-existing biological "noise" in the system. That is, the emergent noise derives from the disease itself, i.e., systemic maladaptations or dysfunctions caused by past higher intensity stressors and disease-related factors [99-101] (Figure 2).

This conceptualization is somewhat similar to the basis for using vaccines in preventive health care. For example, cowpox vaccines given to a person in advance of contracting the more deadly, crossadapted smallpox virus were able to prevent the latter infection. In nanomedicine, some investigators are studying tumor-derived exosomes (nanoscale vesicles) vaccines to treat existing cancers [107]. Notably, some homeopaths in India already use breast cancer tissuederived, homeopathically-prepared nanomedicines in some of their cancer treatment regimens [20,108-110]. For conditions that rely on immune function, this strategy may be particularly useful.

Moreover, complex adaptive systems can interact with environmental factors to amplify responses disproportionately to low intensity stimuli, drugs, or other stimuli with salience for the organism. Global and local motifs of recurring interaction patterns within and across a CAS can affect one another [95]. The timing of even a small stimulus can lead to major shifts and even disruption of the ongoing nonlinear dynamics of the whole system. For instance, under a certain set of conditions, with a stimulus that is properly timed and placed in the system, bifurcations of dynamics or cusp catastrophe events can suddenly manifest (Figure 3 ).

Notably, with homeopathic nanomedicines, timing of dose can alter the direction of the host response. For example, Table 1 shows the results of an animal study in which timing the administration of the homeopathic medicine relative to the time of an experimentally-

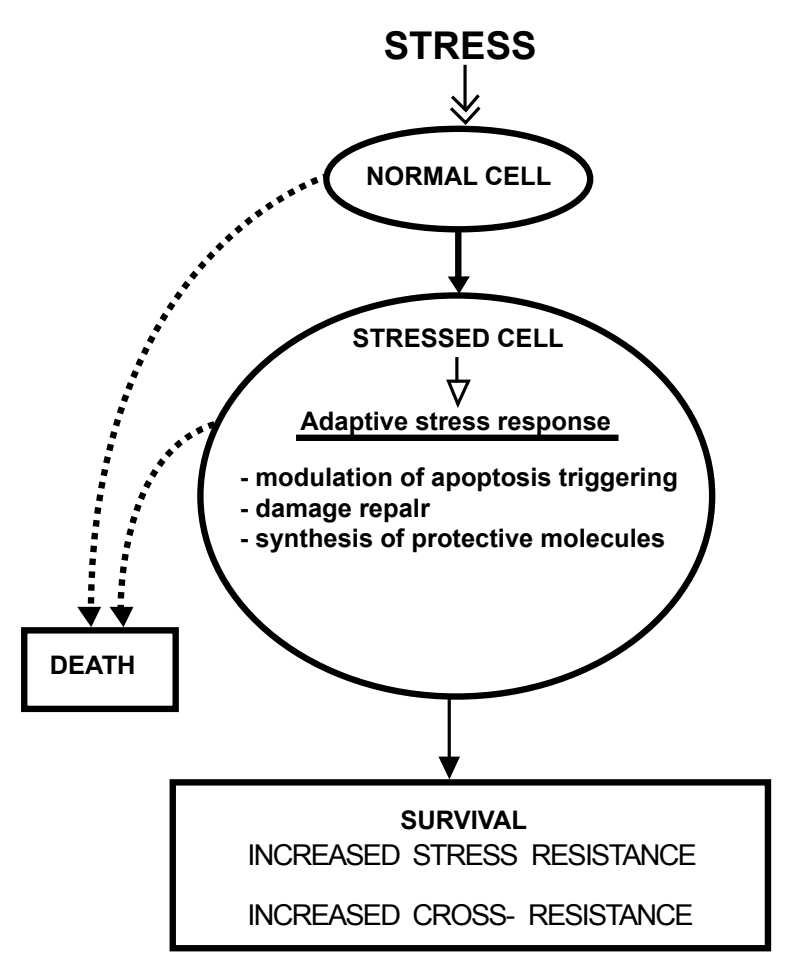

Figure 2: Model for induction of therapeutic adaptive changes from an environmental stressor [97].

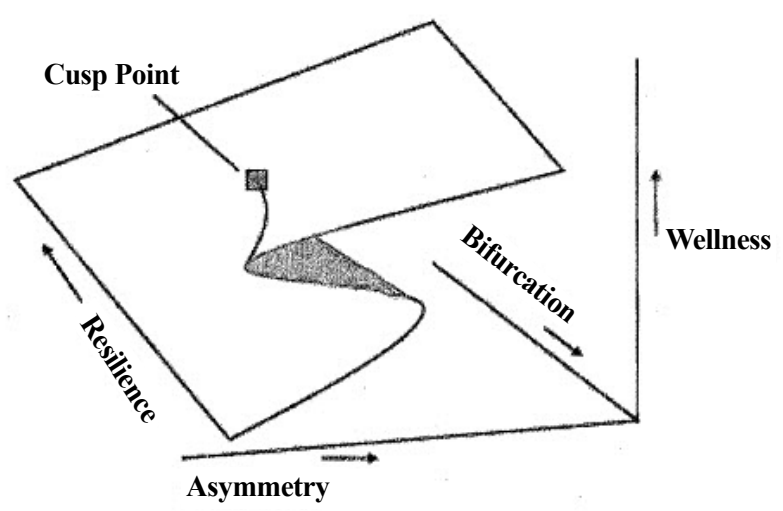

Figure 3: Nonlinear dynamics in a complex adaptive system (CAS): cusp catastrophe model for resilience and wellness in a CAS (cell or organism) [71]. Abrupt shifts from one state to another can occur with system conditions triggered at certain critical dynamical points.

induced acute injury changes the direction of the effects of treatment compared with saline control treatment [74]. Giving the medicine before the injury increases the subsequent edema response from the experimental injury. It is only after the injury has occurred that the medicine leads to reduction in severity of the edema. Although seemingly abstract, such nonlinear dynamical changes can lead to lasting functional reorganization of the system dynamics [68]. For desirable therapeutic benefits, the disruption of disease dynamics could also give the system an opportunity to self-re-organize back into a healthier mode of functioning [70,71,88,111-113] (Figures 1 and 3). 
Citation: Bell IR, Sarter B, Koithan M, Standish LJ, Banerji P, et al. (2013) Nonlinear Response Amplification Mechanisms for Low Doses of Natural Product Nanomedicines: Dynamical Interactions with the Recipient Complex Adaptive System. J Nanomed Nanotechol 4: 179. doi:10.4172/2157-7439.1000179

Page 5 of 13

From the perspective of an organism as a CAS, disease and aging lead to a loss of complexity in the system dynamics [114-117]. As a result, the organism is less flexible and resilient against adverse endogenous or exogenous factors. One measure of complexity known as multiscale entropy (MSE) analyzes time series physiological data across different time scales to determine recurring patterns. For example, Costa et al. [114] showed quantitative individual differences in heart rate variability complexity with MSE as a function of age and health status [114,118]. Younger healthy persons show greater complexity compared with older healthy persons. However, like older people, unhealthy individuals of any age, i.e., people with congestive heart failure, also exhibit less heart rate variability complexity. In this case, reduced complexity in heart rate variability leaves the individual more susceptible to aberrant beats and resultant life-threatening arrhythmias.

Restoring optimal complexity to system dynamics underlies the therapeutic goal $[59,60,88,104]$. Systemic resilience to future stressors emerges with a meta-flexibility to adapt more effectively to environmental stressors/agents that impinge on the system. The beneficial therapeutic outcome results from the interaction of the treatment with the organism [71].

\section{Organism-Dependent Response Amplification Phe- nomena}

Homeopathic researchers have highlighted three endogenous amplification phenomena as ways in which a relevant exogenous stimulus such as a one-time or infrequently-pulsed dose of a salient NP could affect the whole organism. These phenomena are: hormesis [99,119], time-dependent sensitization [21], and stochastic resonance [120]. All three forms of endogenous amplification share an essential feature. That is, the treatment agent must possess salience as a subtoxic or nontoxic, but biologically meaningful, danger signal to the organism.

The low level foreign stimulus signifies a relevant environmental stressor or future potential biological threat to survival. In short, all three mechanisms depend on the nonlinear interaction of the low dose (or signal) with the living organism as a complex adaptive system (CAS) [60]. Table 2 summarizes the features of the proposed mechanisms. Initial studies suggest that doses of certain nanoparticles can alter the nonlinear dynamics of a complex biological system in clinically meaningful ways, e.g., to offset expression of autoimmune patterns [121].

Hormesis (Figure 4) is a nonlinear dose-response relationship. In hormesis, low doses of an agent or a different, cross-adapted agent can initiate beneficial adaptive responses that can either reverse existing toxicity or protect the organism against future higher (toxic) dose exposures [122]. More than 8,000 scientific papers have now demonstrated hormetic effects as a manifestation of biological plasticity [103]. Low doses of nanoparticles can cause hormesis [105,123]. Other studies have demonstrated that low doses of homeopathically-prepared metals, including cadmium and arsenic, can produce beneficial hormetic reversal of effects of higher, toxic doses of the same or crosssensitized agent on heat shock protein activation patterns [124]. Heat shock proteins are among the biological modulators of the stress response networks involved in adaptation to various environmental stressors [94,125].

In the homeopathic NP dose range, the low dose hormetic effects can take on the sinusoidal oscillatory dose-response patterns reported in various preclinical and clinical studies $[5,73,126]$. To avoid toxicity but still elicit the adaptive response of hormesis with nanoforms of some agents such as poisonous plants, that are otherwise toxic at higher doses, extremely low doses, i.e., picogram/milliliter to low nanogram levels, may be necessary [21].

Available estimates of concentrations of source NPs in homeopathic metal remedies range from a low of $0-10$ picograms/milliliter to $2-4$ nanograms/milliliter [3]. If (a) nanoscale forms of a drug can lower pharmacological dose requirements up to 1000 times compared with conventional bulk forms of the same drug to cause direct, local receptor effects [50] and (b) some nanoparticles can be toxic at 1 nanomolar concentrations $[51,52]$, then the corresponding hormetic dose ranges to elicit adaptive effects in the opposite direction for each given agent would have to fall below an already very low dose [21].

\begin{tabular}{|c|c|c|}
\hline $\begin{array}{l}\text { Nonlinear Amplification } \\
\text { Phenomenon }\end{array}$ & Nanomedicine Dose Characteristic & Signal Role of Nanomedicine Dose \\
\hline Hormesis & $\begin{array}{l}\text { Low dose as mild stressor } \\
\text { Depends on interaction with organism more than on specific } \\
\text { pharmacological nature of stressor/agent } \\
\text { Able to initiate adaptive response }\end{array}$ & $\begin{array}{l}\text { Low dose evokes response in opposite direction to that for high dose. } \\
\text { Cross-adaptation between chemically-unrelated stressors/agents } \\
\text { observed. } \\
\text { Nanoparticles can evoke hormesis. }\end{array}$ \\
\hline $\begin{array}{l}\text { Time-Dependent } \\
\text { Sensitization (TDS) }\end{array}$ & $\begin{array}{l}\text { Low dose as danger signal } \\
\text { Pulsed dose administration (repeated intermittent timing) } \\
\text { Salient threat or stressor for the system }\end{array}$ & $\begin{array}{l}\text { Passage of time between discrete doses leads to progressive growth of } \\
\text { host response to next dose. } \\
\text { Overly frequent doses will cause sequential oscillatory reversals in } \\
\text { direction of response from dose to dose. } \\
\text { Cross-sensitization between chemically-unrelated stressors/agents } \\
\text { observed. } \\
\text { Homeopathic medicines can initiate and elicit TDS. }\end{array}$ \\
\hline Stochastic Resonance (SR) & $\begin{array}{l}\text { Low dose as signal } \\
\text { Concomitant background noise present (systemic biology of the } \\
\text { organism-wide emergent disease process) } \\
\text { Salient signal for the system }\end{array}$ & $\begin{array}{l}\text { Host response amplification in response to the weak signal value of the } \\
\text { low dose by the background noise in the system. } \\
\text { SR in animal sensory systems for detecting approach of a dangerous } \\
\text { predator observed. } \\
\text { SR between two quantum dot (small NPs) and with carbon nanotubes or } \\
\text { metal NPs observed. }\end{array}$ \\
\hline
\end{tabular}

Table 2: Proposed low dose effects: mediating processes for therapeutic effects from pulsed low doses of nanomedicines in a complex adaptive system. Amplification phenomena depend on nonlinear interactions with the dynamics of the organism as a complex adaptive system. 
Citation: Bell IR, Sarter B, Koithan M, Standish LJ, Banerji P, et al. (2013) Nonlinear Response Amplification Mechanisms for Low Doses of Natural Product Nanomedicines: Dynamical Interactions with the Recipient Complex Adaptive System. J Nanomed Nanotechol 4: 179. doi:10.4172/2157-7439.1000179

Page 6 of 13

Time-dependent sensitization (TDS) is another organismdependent response amplification process. TDS involves the progressive amplification of the system's response to a given low dose of an agent or stressor with the mere passage of time between the initial and subsequent re-exposures to the same or a cross-sensitized agent or stressor. The dose remains low, and the initial exposure does not elicit much, if any, overt response. However, each subsequent repeat exposure to the same or a cross-sensitized stressor or agent elicits an increasingly larger response. Immune system involvement is not necessary for TDS to occur; the process is especially common in certain central nervous system pathways. Neuronal and endocrine stress response pathways may be more important than immune function in TDS [127-131].

This type of sensitization and cross-sensitization is a welldocumented phenomenon between agents and stressors of very different classes, especially affecting the central nervous system [131]. Thus, to initiate TDS, the stressful or foreign nature of a drug for the individual is more important than the specific pharmacological properties of the agent [131]. Overly frequent repetition of a sensitizing agent can also cause a within-subject oscillatory reversal in direction of the response [132]. Two different placebo-controlled, doubleblind studies using electroencephalographic alpha effects have shown that homeopathically-prepared medicines initiate and elicit timedependent sensitization (response amplification) in human subjects [133,134] (Figure 5).

Stochastic resonance (SR) is amplification of a small periodic signal by concomitant presentation within a larger random noise background pre-existing within the complex system [135]. Stochastic resonance is a common phenomenon in biological systems, especially neural networks and sensory systems. One example of SR in animals is the capacity for sensory detection of weak environmental signals heralding arrival of a predator threat [136,137]. Figures 6 and 7 illustrate the mechanism and nature of stochastic resonance. The graphs show a sinusoidal response dependent upon the different noise levels [136] and a peak value at a specific noise level [135]. Such sinusoidal doseresponse phenomena are similar to the sinusoidal dose-response curves noted for homeopathically-prepared medicines in a bacterial cell metabolism model [126].

In statistical physics, Joshi has also shown that weak coupling in a

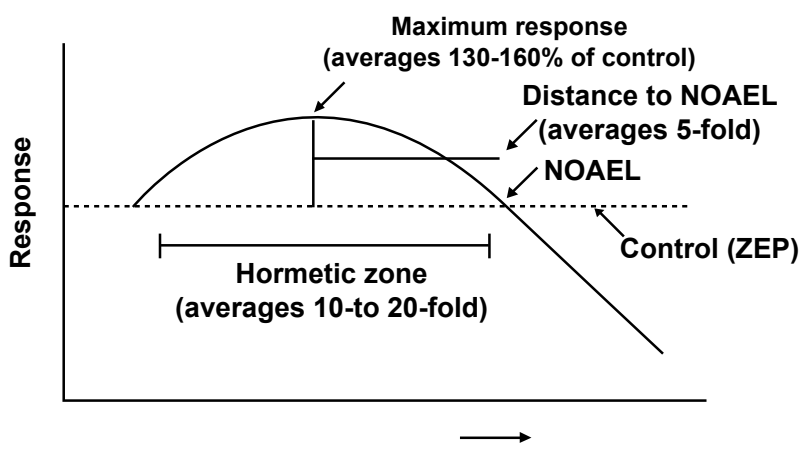

NOAEL=no observed adverse effect level ZEP=zero equivalent point

Figure 4: Hormesis is a nonlinear dose-response relationship in which low doses stimulate adaptive changes in the organism whereas high doses inhibit function as conventional drugs or toxicants [187].

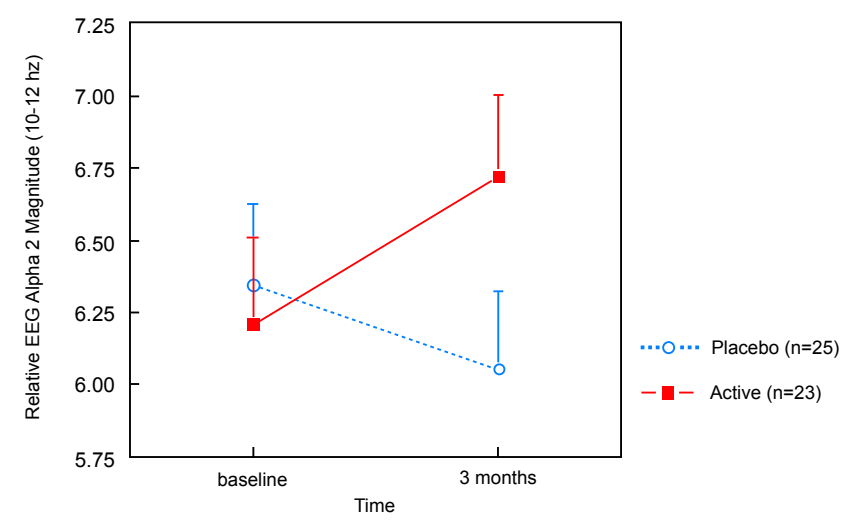

Figure 5: Time-dependent sensitization of electroencephalographic (EEG) alpha-2 band (10-12 hertz) magnitude during olfactory sniffs of individualized homeopathic medicine (liquid form) by people with fibromyalgia [133]. Controlled for baseline mood, medications, and placebo sniffing in both groups. Verum (Active) dose was "lower" by conventional pharmacological criteria at the 3-month test than at baseline test, i.e., "higher" in homeopathic potency. However, EEG response had nonetheless grown in size over 3 months of once-daily oral treatments between the prepost treatment olfactory-administered laboratory test sessions.

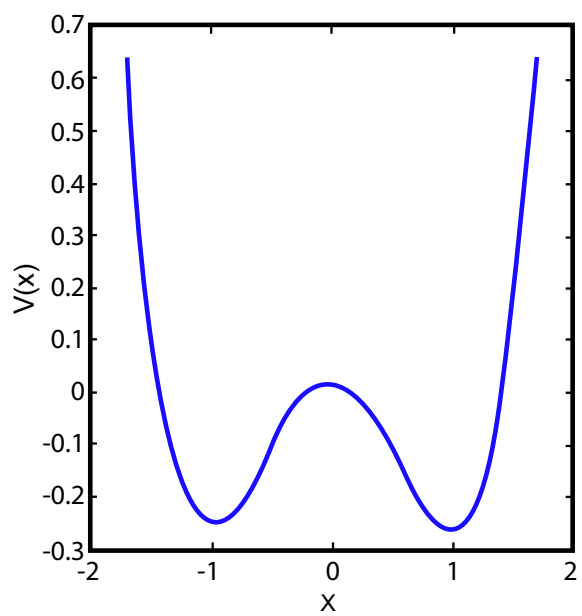

Note: The system response depends upon the noise level. Stochastic resonance occurs in biological systems, including sensory systems detecting weak signals of danger from predators and neural networks

Figure 6: The mechanism of stochastic resonance. The double well potential $V(x)$ represents a physical system with two stable states. In absence of noise, a particle, which at one time is within one of the two wells, relaxes towards the intrawell minimum and then stops. When stochastic perturbation is added to this system the particle can hop between the two wells with a rate predicted by reaction-rate theory. If a weak periodic forcing is present the overall potential minimum changes periodically from one side to the other. Stochastic resonance happens when the typical escape time from the lower barrier and the periodic forcing are synchronized [136].

double quantum dot system can exhibit stochastic resonance [138]. A substantial proportion of NPs in at least some homeopathic medicines fall into the quantum dot size range of 1-10 nanometers in diameter [3]. Carbon nanotube transistors can also exhibit SR [139]. Biological systems are typically associated with $1 / \mathrm{f}$ spectrum noise [140]. Introducing $1 / \mathrm{f}$ noise into silicon-based nanomechanical resonators in nanoelectronics can lead to SR-based signal amplification [141]. 
Citation: Bell IR, Sarter B, Koithan M, Standish LJ, Banerji P, et al. (2013) Nonlinear Response Amplification Mechanisms for Low Doses of Natural Product Nanomedicines: Dynamical Interactions with the Recipient Complex Adaptive System. J Nanomed Nanotechol 4: 179. doi:10.4172/2157-7439.1000179

Page 7 of 13

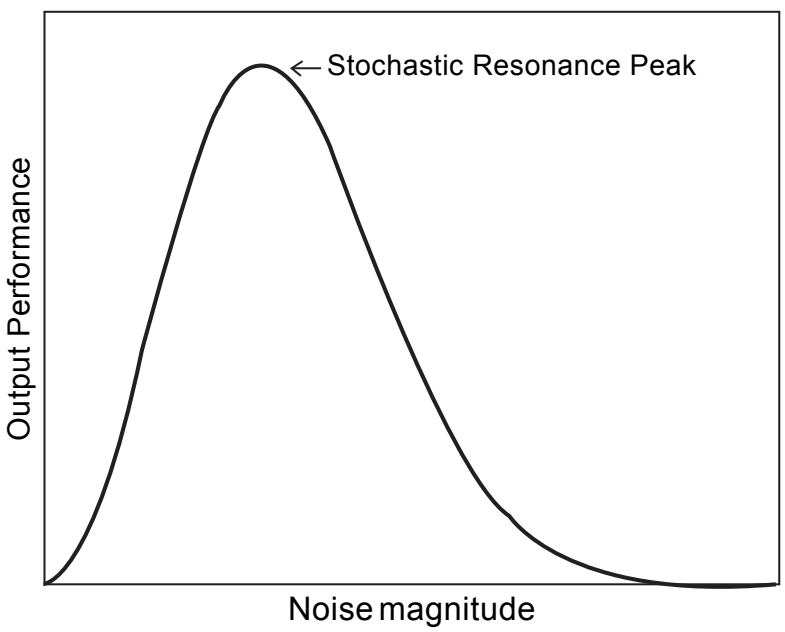

Note: The "noise" in the person as a complex adaptive system would be the disease-related unique emergent disturbances of function across the genetic and other adaptive networks that comprise that individual [183]. The SR amplification would depend upon the similarity of the preexisting biological "noise" of endogenous disease to the signal quality of the low dose of homeopathic medicine. The correct medicine would have to possess a capacity to elicit a similar set of adaptive disturbances and dysfunctions if given at higher dose

Figure 7: Typical curve of output performance versus input noise magnitude, for systems capable of stochastic resonance (SR). For small and large noise, the performance metric (e.g., SNR, mutual information, Fisher information, correlation, discrimination index) is very small, while some intermediate nonzero noise level provides optimal performance [135].

Thus, for SR to occur, the pulsed dosing regimens of homeopathic nanomedicines spaced in time would present each low nanostructured dose as a discrete, small danger signal input. The small signal of the medicine as input would occur against the background of the preexisting endogenous biological noise from the unique maladaptive dysfunctional patterns associated with emergent disease in the individual organism $[120,142,143]$. The medicine signal "needs" the presence of the disease noise for amplification of effects.

The organism would detect the threat value of the isolated dose and respond nonlinearly with adaptive changes. If the salience addresses the organism-wide disease process, then the response would be more pronounced, perhaps coordinated by the central nervous system [144]. For example, one double-blind randomized controlled trial compared changes in the prefrontal Electroencephalographic (EEG) cordance response to the first dose of an individually-matched homeopathic medicine in subsequently exceptionally good clinical responders versus all other study participants [144]. The EEG cordance verum responders to the first dose showed not only initial EEG differences, but also significantly better clinical improvements that diverged from those of verum non-responders and placebo patients. The prefrontal region of the brain is involved in planning, coordinating executive decisionmaking capacity, and regulating emotional and sentient experiences. Prefrontal cortex also regulates the hypothalamic-pituitary-adrenal axis of the stress response pathways [145].

If the salience is less relevant to the organism's biology as an integrated dynamical system, the endogenous protective response may be more local and limited in scope. Non-salient NPs at low pulsed doses would have minimal transient effects either in terms of overall toxicity or therapeutic effects at the level of organizational scale of the organism. Response mechanisms may not engage the central nervous system or other parts of the stress response network as fully.

To date, the limited attempts to use SR for clinical problems include adding vibrational noise to the feet to enhance signal detection in failing sensory systems, e.g., for balance problems in the elderly [146]. In contrast, homeopathic dosing may instead take advantage of the established biological disease "noise" and the stress response pathways first responders by instead adding a weak but highly salient signal into the noise.

The reader is referred to other papers on these low dose, organismdependent response amplification phenomena for more in-depth explanations $[21,99,119,120]$. Given the quantum dot size of some homeopathically-prepared metal NPs [3], it is not also possible to rule out quantum mechanical phenomena in some of the homeopathicallyinduced low dose responses [147-149]. Quantum dots per se possess inherent unpredictability in their properties [150-152] as another potential explanation for the variability and anomalies of homeopathic medicine effects. Even so [136,153], the evidence suggests that these three adaptive biological amplification mechanisms are scientifically indicated as a starting point for systematic empirical studies into how homeopathically-manufactured nanomedicines could initiate healing responses.

It is possible that certain dose ranges of NPs evoke one or more of these processes, but not others. In homeopathic treatment of chronic diseases, for instance, the scope of possible medicine selections is in the thousands. A key homeopathic practice principle is the need to select a medicine whose toxic properties are a very similar match to the unique pattern of individualized symptoms that the patient already experiences as a whole. Without the comprehensive match to the organism's adaptive susceptibilities, an "active" medicine at low dose has little or no effect.

With a good match, the medicine mobilizes a nonlinear cascade of changes leading to recovery across the entire organism. In parallel, it may require a more salient match between the signal quality of the small medicine dose and the endogenous emergent "noise" of the disease dysfunctions occurring within the system to evoke stochastic resonance. At higher potency medicines, SR could account for the hormesis-like phenomena observed and explain in part why the doseresponse curve is sinusoidal in nature [126].

On the other hand, simple nanoparticle-based biological amplification of beneficial herbal or mineral salt effects may be more relevant than SR at very low potencies (triturated and/or minimally diluted and succussed nanoparticles). In this scenario, repeated doses might lead to time-dependent sensitization. Acute illnesses can respond well to very low potencies of homeopathically-prepared medicines [154]. In homeopathy, "low potencies" translate into minimally diluted and succussed (agitated) medicines, probably containing both bulk and nanoforms of source material.

In fact, many homeopathic clinicians report the ability to treat a large proportion of the population for acute infectious illnesses with only a few different medicines. The direction of the response depends upon the state of the organism at the time of the dose. If an injury is already established, the response direction is toward recovery. However, if the injury occurs after the exposure to the homeopathic nanomedicine, the response may be amplified in an adverse direction [74]. 
Citation: Bell IR, Sarter B, Koithan M, Standish LJ, Banerji P, et al. (2013) Nonlinear Response Amplification Mechanisms for Low Doses of Natural Product Nanomedicines: Dynamical Interactions with the Recipient Complex Adaptive System. J Nanomed Nanotechol 4: 179. doi:10.4172/2157-7439.1000179

Page 8 of 13

\section{Experimental Questions}

The above points raise many questions. For instance, under what experimental and clinical conditions do hormesis, stochastic resonance, and/or time-dependent sensitization come into play during adaptive responses to homeopathically-prepared nanomedicines and other NPs? Can quantum mechanical phenomena such as quantum confinement, quantum coherence, and/or quantum entanglement be experimentally demonstrated with some very small sized homeopathically-prepared medicine NPs and their interactions with living organisms? Under what circumstances might some homeopathic nanomedicines prevent disease [155], or is their primary role in treatment of pre-existing disease?

Is the polydisperse nature of homeopathic nanomedicines as crudely -made top down naturally-sourced NPs a clinical advantage or disadvantage? For public health purposes, providing multiple NP sizes in a given dose may facilitate effects across more individuals. Some evidence suggests that including different sizes of the same source material NPs in antennas or multi-component nano-ensembles leads to better self-similar amplification of effects [138,142,143,156-160], including stochastic resonance $[139,142,161]$. For higher potencies made traditionally in glass-contained liquids, the release and presence of nanosilica and/or nanosilicon in solution from succussions in glassware could contribute a drug-delivery vehicle and a biological $[34,37,162]$, microelectronic and photonic amplifier [163,164].

Some homeopathically-manufactured nanostructures from bacteria emit characteristic electromagnetic signals that can be detected and recorded [165]. Agitation of the solutions during manufacturing is necessary to generate such phenomena. Nanosilicon may also acquire quantum mechanical properties at small quantum dot sizes [42,164,166,167], a feature that may help account for certain other observations in the homeopathic drug development research literature $[147,148,168]$. Doping of the nanosilicon and nanosilica by the medicine source material and other trace contaminants in solution during early preparation steps [9] may add more memory and amplification mechanisms $[164,169,170]$.

Other components of the manufacturing process could change the therapeutic potential and safety of homeopathic nanomedicines. Thus, what are the roles of lactose and ethanol in modifying the natural source nanoparticle surfaces and properties? Ethanol can affect nanosilica particle sizes and shapes [33]. Evidence on homeopathicallyprepared materials and on modern nanoparticles suggests that lactose on the NP surface can change the physico-chemical properties [11] and/or ability to enter cancer cells [23]. Surface charge can also affect cancer cell response to NP treatments [171].

For treatment of conditions such as specific cancers, some homeopaths use a diagnosis-driven protocol approach for selecting homeopathically-manufactured medicine $[108,109,172]$. The diagnosisbased selection of medicines facilitates providing care from a public health perspective to a large number of patients. Bulk herb extracts of Ruta graveolens, for instance, exert anti-cancer effects [173,174]; and an oral nanoscale formulation of one of its main constituents, rutin, has good bioavailability [175].

The nanoparticle form of calcium phosphate has antiproliferative and pro-apoptotic effects on glioma [176] and osteosarcoma [54] cells. Similarly, their homeopathically-manufactured counterparts, e.g., Ruta graveolens 6C and Calcarea Phosphorica 3X [172], are part of a leading combination anti-cancer protocol for gliomas $[108,172]$. Homeopathic
Calcarea Phosphorica 3X combined with the plant-derived homeopathic medicine Symphytum 200C and another homeopathic medicine is used for osteosarcomas in India $[20,108,109,172]$. In low potency vs controls, homeopathic Symphytum 6 C can also enhance bone formation around experimental titanium implants in rats [177].

Furthermore, silica NPs also biologically amplify the antineoplastic effects of a traditional snake venom medicine against breast and prostate cancer as well as multiple myeloma $[162,178,179]$. Extensive nanoscience evidence demonstrates not only biological amplification effects of nanosilica, but also bottom up self-assembly of silica-based nanostructures using biological materials as templates [180]. Could homeopathic plant or other source material-modified silica nanostructures retain structural and functional information for reproduction into higher potencies, similar to plant-synthesized silver and gold NPs [40] or nanosilica doped or coated with other materials [181]? Silicatein enzymes from sponges and other plant materials can provide unique structure-guiding proteins [182]. Stochastic resonance $[138,161]$ involving plant-modified nanosilicon quantum dots is a potential amplification mechanism from interaction with a living system for which the specific homeopathically-prepared medicine is a salient but mild danger signal $[138,183]$.

As noted earlier, the more widely-used classical homeopathic prescribing method is patient-, not diagnosis-centered. In classical homeopathy, the patient's complete pattern of biological, psychological, emotional, and social symptoms and behaviors in all subsystems is weighted and integrated to choose a single homeopathic medicine for the person as a whole. Such a medicine then reportedly initiates a healing response across the entire individual as an indivisible organism $[1,184]$. In most clinical situations, given time and resources, homeopaths prefer the patient-centered approach to selecting their medicines. Nonetheless, with the ability to understand better the nature of homeopathically-manufactured natural nanomedicines and their interactions with living systems, the relative advantages and disadvantages of diagnosis-based versus patient-centered selection of natural nanomedicines also becomes a relevant empirical question.

\section{Conclusions}

Homeopathic medicines have enjoyed widespread use in treatment of acute and chronic conditions, including infections $[15,64,154]$ and cancers $[20,109,172]$. During over more than two centuries of real-world use, millions of people in many different countries have reported excellent safety, tolerability, and clinical benefits from these natural product-based nanomedicines [58,154]. Pulsed low doses can minimize risks from in vivo accumulation of NPs. Thus, relying on the interaction of NPs with the recipient organism as a complex adaptive system, rather than using NPs as if they were super-potent conventional bulk drugs, could lead to enhanced effects and safety benefits.

In clinical practice, homeopaths emphasize (a) selection of the therapeutic agent for its salience to the pre-existing emergent pattern of dysfunctions (symptoms) across the entire organism, rather than for blockade of local receptors in one symptomatic organ of the body; and (b) a pulsed discrete dosing approach that pauses or stops treatment once transient worsening or initial improvement has begun. Treatment resumes with repeat dosing only if improvement stops short of full recovery. As a result, homeopathic nanomedicines are different from conventional bulk drugs and natural products because of their nature, clinical indications, low dose levels, and pulsed or intermittent dosing schedules. 
Citation: Bell IR, Sarter B, Koithan M, Standish LJ, Banerji P, et al. (2013) Nonlinear Response Amplification Mechanisms for Low Doses of Natural Product Nanomedicines: Dynamical Interactions with the Recipient Complex Adaptive System. J Nanomed Nanotechol 4: 179. doi:10.4172/2157-7439.1000179

Page 9 of 13

On the one hand, homeopathic practice theory, combined with complex systems science, could inform new treatment strategies for dosing nanomedicines more safely [58]. Relying on the organism as self-organized nonlinear amplifier, rather than the nanoparticles alone to carry the change, could lead to novel treatment approaches. Hormesis, time-dependent sensitization, and stochastic resonance offer a starting place for research on endogenous amplification mechanisms for pulsed low doses of nanomedicines to initiate clinically significant emergent effects.

On the other hand, the historical methods for homeopathic medicine manufacturing might benefit from updating, based on advances in modern nanotechnology [21]. Making more consistent homeopathic nanomedicines with well-characterized particle properties could result in more reliable effects in both research and clinical contexts $[185,186]$. Integrating the insights, technical manufacturing expertise, and particle characterization procedures of modern nanotechnology with the green manufacturing approach, clinical medicine selection, and pulsed low dosing approaches of homeopathic nanomedicine could lead to major advances in the field [187]. The outcome for contemporary nanomedicine can be more effective and safer translational applications to improve patient care.

\section{Competing interests}

Dr. Bell is a consultant to Standard Homeopathic/HylandsInc, a U.S.-based manufacturer of homeopathic medicines. The company did not provide any financial support for the studies cited or for publication costs for the present paper.

\section{Acknowledgement}

This study was supported in part by National Center for Complementary and Alternative Medicine grant T32 AT01287 (PI: IRB)

\section{References}

1. Fisher P (2012) What is homeopathy? An introduction. Front Biosci (Elite Ed) 4: 1669-1682.

2. Ullman D (2006) Let's have a serious discussion of nanopharmacology and homeopathy. FASEB J 20: 2661.

3. Chikramane PS, Suresh AK, Bellare JR, Kane SG (2010) Extreme homeopathic dilutions retain starting materials: A nanoparticulate perspective. Homeopathy 99: 231-242.

4. Upadhyay RP, Nayak C (2011) Homeopathy emerging as nanomedicine. Int J High Dilution Res 10: 299-310.

5. Stovbun SV, Kiselev AV, Zanin AM, Kalinina TS, Voronina TA, et al. (2012) Effects of physicochemical forms of phenazepam and Panavir on their action at ultra-low doses. Bull Exp Biol Med 153: 455-458.

6. Ives JA, Moffett JR, Arun P, Lam D, Todorov TI, et al. (2010) Enzyme stabilization by glass-derived silicates in glass-exposed aqueous solutions. Homeopathy 99: 15-24.

7. Demangeat JL (2010) NMR relaxation evidence for solute-induced nanosized superstructures in ultramolecular aqueous dilutions of silica-lactose. J Mol Liq 155: 71-79.

8. Demangeat JL (2013) Nanosized solvent superstructures in ultramolecular aqueous dilutions: twenty years' research using water proton NMR relaxation. Homeopathy 102: 87-105.

9. Witt CM, Lüdtke R, Weisshuhn TE, Quint P, Willich SN (2006) The role of trace elements in homeopathic preparations and the influence of container material, storage duration, and potentisation. Forsch Komplementmed 13: 15-21.

10. Rao ML, Roy R, Bell IR, Hoover R (2007) The defining role of structure (including epitaxy) in the plausibility of homeopathy. Homeopathy 96: 175-182.

11. Chikramane PS, Kalita D, Suresh AK, Kane SG, Bellare JR (2012) Why extreme dilutions reach non-zero asymptotes: a nanoparticulate hypothesis based on froth flotation. Langmuir 28: 15864-15875.

12. Rey $L$ (2003) Thermoluminescence of ultra-high dilutions of lithium chloride and sodium chloride. Physica A 323: 67-74.
13. Liu Y, Kathan K, Saad W, Prud'homme RK (2007) Ostwald ripening of betacarotene nanoparticles. Phys Rev Lett 98: 036102.

14. Elia V, Napoli E, Germano R (2007) The 'Memory of Water': an almost deciphered enigma. Dissipative structures in extremely dilute aqueous solutions. Homeopathy 96: 163-169.

15. Bell IR, Schwartz GE, Boyer NN, Koithan M, Brooks AJ (2013) Advances in Integrative Nanomedicine for Improving Infectious Disease Treatment in Public Health. Eur J Integr Med 5: 126-140.

16. Kayne SB (2006) Homeopathic Pharmacy: Theory and Practice, 2e: Churchill Livingstone.

17. DeCastro CL, Mitchell BS (2002) Nanoparticles from mechanical attrition. In Baraton MI, editor. Synthesis, Functionalization, and Surface Treatment of Nanoparticles. Valencia, CA: American Scientific Publisher. pp. 1-15.

18. Bell IR, Koithan M (2012) A model for homeopathic remedy effects: low dose nanoparticles, allostatic cross-adaptation, and time-dependent sensitization in a complex adaptive system. BMC Complement Altern Med 12: 191.

19. Bell IR, Koithan M, Brooks AJ (2013) Testing the nanoparticle-allostatic crossadaptation-sensitization model for homeopathic remedy effects. Homeopathy 102: 66-81.

20. Bell IR, Sarter B, Koithan M, Banerji P, Banerji P, et al. (2013) Integrative nanomedicine: treating cancer with nanoscale natural products. Global Advances in Health and Medicine in press.

21. Bell IR, Schwartz GE (2013) Adaptive network nanomedicine: an integrated model for homeopathic medicine. Front Biosci (Schol Ed) 5: 685-708.

22. Sur I, Altunbek M, Kahraman M, Culha M (2012) The influence of the surface chemistry of silver nanoparticles on cell death. Nanotechnology 23: 375102 .

23. Sur I, Cam D, Kahraman M, Baysal A, Culha M (2010) Interaction of multifunctional silver nanoparticles with living cells. Nanotechnology 21: 175104.

24. Panacek A, Kvítek L, Prucek R, Kolar M, Vecerova R, et al. (2006) Silver colloid nanoparticles: synthesis, characterization, and their antibacterial activity. $J$ Phys Chem B 110: 16248-16253.

25. Caron V, Willart JF, Lefort R, Derollez P, Danède F, et al. (2011) Solid state amorphization kinetic of alpha lactose upon mechanical milling. Carbohydr Res 346: 2622-2628.

26. Tavares Cardoso MA, Talebi M, Soares PA, Yurteri CU, van Ommen JR (2011) Functionalization of lactose as a biological carrier for bovine serum albumin by electrospraying. Int J Pharm 414: 1-5.

27. Liu L, Randolph TW, Carpenter JF (2012) Particles shed from syringe filters and their effects on agitation-induced protein aggregation. J Pharm Sci 101 2952-2959.

28. Bhattacharyya SS, Mandal SK, Biswas R, Paul S, Pathak S, et al. (2008) In vitro studies demonstrate anticancer activity of an alkaloid of the plant Gelsemium sempervirens. Exp Biol Med (Maywood) 233: 1591-1601.

29. Witt C, Lüdtke R, Weisshuhn TE, Willich SN (2005) High homeopathic potencies are different from potentized solvent when investigated with the REDEM technology. Forsch Komplementarmed Klass Naturheilkd 12: 6-13.

30. Tang C, Zhou T, Yang J, Zhang Q, Chen F, et al. (2011) Wet-grinding assisted ultrasonic dispersion of pristine multi-walled carbon nanotubes (MWCNTs) in chitosan solution. Colloids Surf B Biointerfaces 86: 189-197.

31. Keck CM, Müller RH (2006) Drug nanocrystals of poorly soluble drugs produced by high pressure homogenisation. Eur J Pharm Biopharm 62: 3-16.

32. Merisko-Liversidge E, Liversidge GG (2011) Nanosizing for oral and parentera drug delivery: a perspective on formulating poorly-water soluble compounds using wet media milling technology. Adv Drug Deliv Rev 63: 427-440.

33. Yoo JW, Yun DS, Kim HJ (2006) Influence of reaction parameters on size and shape of silica nanoparticles. J Nanosci Nanotechnol 6: 3343-3346.

34. Mahony D, Cavallaro AS, Stahr F, Mahony TJ, Qiao SZ, et al. (2013) Mesoporous Silica Nanoparticles Act as a Self-Adjuvant for Ovalbumin Model Antigen in Mice. Small.

35. Winter M, Beer HD, Hornung V, Krämer U, Schins RP, et al. (2011) Activation of the inflammasome by amorphous silica and $\mathrm{TiO} 2$ nanoparticles in murine dendritic cells. Nanotoxicology 5: 326-340. 
Citation: Bell IR, Sarter B, Koithan M, Standish LJ, Banerji P, et al. (2013) Nonlinear Response Amplification Mechanisms for Low Doses of Natural Product Nanomedicines: Dynamical Interactions with the Recipient Complex Adaptive System. J Nanomed Nanotechol 4: 179. doi:10.4172/2157-7439.1000179

36. Simovic S, Ghouchi-Eskandar N, Sinn AM, Losic D, Prestidge CA (2011) Silica materials in drug delivery applications. Curr Drug Discov Technol 8: 269-276.

37. Wang T, Jiang H, Zhao Q, Wang S, Zou M, et al. (2012) Enhanced mucosa and systemic immune responses obtained by porous silica nanoparticles used as an oral vaccine adjuvant: effect of silica architecture on immunological properties. Int J Pharm 436: 351-358.

38. Ahmad N, Sharma S, Alam MK, Singh VN, Shamsi SF, et al. (2010) Rapid synthesis of silver nanoparticles using dried medicinal plant of basil. Colloids Surf B Biointerfaces 81: 81-86.

39. Chen X, Lou Y, Dayal S, Qu X, Krolicki R, et al. (2005) Doped semiconductor nanomaterials. J Nanosci Nanotechnol 5: 1408-1420.

40. Das S, Das J, Samadder A, Bhattacharyya SS, Das D, et al. (2013) Biosynthesized silver nanoparticles by ethanolic extracts of Phytolacca decandra, Gelsemium sempervirens, Hydrastis canadensis and Thuja occidentalis induce differential cytotoxicity through G2/M arrest in A375 cells. Colloids Surf B Biointerfaces 101: 325-336.

41. Perry CC, Keeling-Tucker $\mathrm{T}$ (1998) Crystalline silica prepared at room temperature from aqueous solution in the presence of intrasilica bioextracts. Chem Commun 23: 2587-2588.

42. Troia A, Giovannozzi A, Amato G (2009) Preparation of tunable silicon q-dots through ultrasound. Ultrason Sonochem 16: 448-451.

43. Aimé C, Mosser G, Pembouong G, Bouteiller L, Coradin T (2012) Controlling the nano-bio interface to build collagen-silica self-assembled networks. Nanoscale 4: 7127-7134.

44. Wu J, Silvent J, Coradin T, Aimé C (2012) Biochemical investigation of the formation of three-dimensional networks from DNA-grafted large silica particles. Langmuir 28: 2156-2165.

45. Winnik FM, Maysinger D (2013) Quantum Dot Cytotoxicity and Ways To Reduce It. Acc Chem Res 46:672-680

46. Armstead AL, Li B (2011) Nanomedicine as an emerging approach against intracellular pathogens. Int J Nanomedicine 6: 3281-3293.

47. Prakash DJ, Arulkumar S, Sabesan M (2010) Effect of nanohypericum (Hypericum perforatum gold nanoparticles) treatment on restraint stressinduced behavioral and biochemical alteration in male albino mice. Pharmacognosy Res 2: 330-334

48. Diwan M, Elamanchili P, Cao M, Samuel J (2004) Dose sparing of CpG oligodeoxynucleotide vaccine adjuvants by nanoparticle delivery. Curr Drug Deliv 1: 405-412.

49. Ahmad Z, Pandey R, Sharma S, Khuller GK (2006) Alginate nanoparticles as antituberculosis drug carriers: formulation development, pharmacokinetics and therapeutic potential. Indian J Chest Dis Allied Sci 48: 171-176.

50. Shirali AC, Look M, Du W, Kassis E, Stout-Delgado HW, et al. (2011) Nanoparticle delivery of mycophenolic acid upregulates PD-L1 on dendritic cells to prolong murine allograft survival. Am J Transplant 11: 2582-2592.

51. Browning LM, Lee KJ, Huang T, Nallathamby PD, Lowman JE, et al. (2009) Random walk of single gold nanoparticles in zebrafish embryos leading to stochastic toxic effects on embryonic developments. Nanoscale 1: 138-152.

52. Zhang H, He X, Zhang Z, Zhang P, Li Y, et al. (2011) Nano-CeO2 exhibits adverse effects at environmental relevant concentrations. Environ Sci Technol 45: $3725-3730$

53. Hong SC, Lee JH, Lee J, Kim HY, Park JY, et al. (2011) Subtle cytotoxicity and genotoxicity differences in superparamagnetic iron oxide nanoparticles coated with various functional groups. Int J Nanomedicine 6: 3219-3231.

54. Shi Z, Huang X, Liu B, Tao H, Cai Y, et al. (2010) Biological response of osteosarcoma cells to size-controlled nanostructured hydroxyapatite. J Biomater Appl 25: 19-37.

55. Greish K, Thiagarajan G, Herd H, Price R, Bauer H, et al. (2012) Size and surface charge significantly influence the toxicity of silica and dendritic nanoparticles. Nanotoxicology 6: 713-723.

56. Kumar V, Kumari A, Guleria P, Yadav SK (2012) Evaluating the toxicity of selected types of nanochemicals. Rev Environ Contam Toxicol 215: 39-121.

57. Witt CM, Lüdtke R, Mengler N, Willich SN (2008) How healthy are chronically il patients after eight years of homeopathic treatment?--Results from a long term observational study. BMC Public Health 8: 413.
58. Bornhoft G, Matthiessen PF (2011) Homeopathy in Healthcare -- Effectiveness, Appropriateness, Safety, Costs: Springer-Verlag, Berlin Heidelberg, Germany, pp. 1-234

59. Bell IR, Koithan M (2006) Models for the study of whole systems. Integr Cancer Ther 5: 293-307.

60. Koithan M, Bell IR, Niemeyer K, Pincus D (2012) A complex systems science perspective for whole systems of CAM research. Forsch Komplementmed 19 7-14.

61. Thompson E, Barron S, Spence D (2004) A preliminary audit investigating remedy reactions including adverse events in routine homeopathic practice. Homeopathy 93: 203-209.

62. Bellavite P, Signorini A (2002) The Emerging Science of Homeopathy. Complexity, Biodynamics, and Nanopharmacology. Berkeley: North Atlantic Books. 408 pp. p.

63. Bellavite $P$ (2003) Complexity science and homeopathy: a synthetic overview. Homeopathy 92: 203-212.

64. Bellavite P, Ortolani R, Pontarollo F, Pitari G, Conforti A (2007) Immunology and homeopathy. 5. The rationale of the 'Simile'. Evid Based Complement Alternat Med 4: 149-163.

65. Buzea C, Pacheco II, Robbie K (2007) Nanomaterials and nanoparticles: sources and toxicity. Biointerphases 2: MR17-71.

66. Bar-Yam Y (1997) Dynamics of Complex Systems. Reading, MA: Perseus Books.

67. Galea S, Riddle M, Kaplan GA (2010) Causal thinking and complex system approaches in epidemiology. Int J Epidemiol 39: 97-106.

68. Szalay MS, Kovács IA, Korcsmáros T, Böde C, Csermely P (2007) Stressinduced rearrangements of cellular networks: Consequences for protection and drug design. FEBS Lett 581: 3675-3680

69. Csermely P, Agoston V, Pongor S (2005) The efficiency of multi-target drugs: the network approach might help drug design. Trends Pharmacol Sci 26: 178182.

70. Hollenstein T (2007) State space grids: analyzing dynamics across development. International Journal of Behavioral Development 31: 384-396.

71. Pincus D, Metten A (2010) Nonlinear dynamics in biopsychosocial resilience. Nonlinear Dynamics Psychol Life Sci 14: 353-380.

72. Mihalik Á, Csermely P (2011) Heat shock partially dissociates the overlapping modules of the yeast protein-protein interaction network: a systems level model of adaptation. PLoS Comput Biol 7: e1002187.

73. Hyland ME, Lewith GT (2002) Oscillatory effects in a homeopathic clinical trial: an explanation using complexity theory, and implications for clinical practice. Homeopathy 91: 145-149.

74. Bertani S, Lussignoli S, Andrioli G, Bellavite P, Conforti A (1999) Dual effects of a homeopathic mineral complex on carrageenan-induced oedema in rats. $\mathrm{Br}$ Homeopath J 88: 101-105.

75. Guastello SJ, Koopmans M, Pincus D (2009) Chaos and Complexity in Psychology: The Theory of Nonlinear Dynamical Systems. New York, Cambridge University Press, USA.

76. Bershteyn A, Hanson MC, Crespo MP, Moon JJ, Li AV, et al. (2012) Robust IgG responses to nanograms of antigen using a biomimetic lipid-coated particle vaccine. J Control Release 157: 354-365.

77. Demento SL, Eisenbarth SC, Foellmer HG, Platt C, Caplan MJ, et al. (2009) Inflammasome-activating nanoparticles as modular systems for optimizing vaccine efficacy. Vaccine 27: 3013-3021.

78. Hornung V, Bauernfeind F, Halle A, Samstad EO, Kono H, et al. (2008) Silica crystals and aluminum salts activate the NALP3 inflammasome through phagosomal destabilization. Nat Immunol 9: 847-856.

79. Zhu M, Li Y, Shi J, Feng W, Nie G, et al. (2012) Exosomes as extrapulmonary signaling conveyors for nanoparticle-induced systemic immune activation. Small 8: 404-412.

80. Zhu M, Tian X, Song X, Li Y, Tian Y, et al. (2012) Nanoparticle-induced exosomes target antigen-presenting cells to initiate Th1-type immune activation. Small 8: 2841-2848.

81. Sun D, Zhuang X, Zhang S, Deng ZB, Grizzle W, et al. (2013) Exosomes are 
Citation: Bell IR, Sarter B, Koithan M, Standish LJ, Banerji P, et al. (2013) Nonlinear Response Amplification Mechanisms for Low Doses of Natural Product Nanomedicines: Dynamical Interactions with the Recipient Complex Adaptive System. J Nanomed Nanotechol 4: 179. doi:10.4172/2157-7439.1000179

endogenous nanoparticles that can deliver biological information between cells. Adv Drug Deliv Rev 65: 342-347.

82. Prado N, Marazuela EG, Segura E, Fernández-García H, Villalba M, et al (2008) Exosomes from bronchoalveolar fluid of tolerized mice prevent allergic reaction. J Immunol 181: 1519-1525.

83. Ristorcelli E, Beraud E, Verrando P, Villard C, Lafitte D, et al. (2008) Human tumor nanoparticles induce apoptosis of pancreatic cancer cells. FASEB J 22 $3358-3369$.

84. Ristorcelli E, Beraud E, Mathieu S, Lombardo D, Verine A (2009) Essential role of Notch signaling in apoptosis of human pancreatic tumoral cells mediated by exosomal nanoparticles. Int J Cancer 125: 1016-1026.

85. Danese A, McEwen BS (2012) Adverse childhood experiences, allostasis, allostatic load, and age-related disease. Physiol Behav 106: 29-39.

86. Karatsoreos IN, McEwen BS (2011) Psychobiological allostasis: resistance, resilience and vulnerability. Trends Cogn Sci 15: 576-584.

87. Karwowski W (2012) A review of human factors challenges of complex adaptive systems: discovering and understanding chaos in human performance. Hum Factors 54: 983-995.

88. Coffey DS (1998) Self-organization, complexity and chaos: the new biology for medicine. Nat Med 4: 882-885.

89. Mohamed BM, Verma NK, Prina-Mello A, Williams Y, Davies AM, et al (2011) Activation of stress-related signalling pathway in human cells upon $\mathrm{SiO} 2$ nanoparticles exposure as an early indicator of cytotoxicity. $J$ Nanobiotechnology 9: 29

90. Meng J, Xing J, Wang Y, Lu J, Zhao Y, et al. (2011) Epigenetic modulation of human breast cancer by metallofullerenol nanoparticles: in vivo treatment and in vitro analysis. Nanoscale 3: 4713-4719.

91. Gong C, Tao G, Yang L, Liu J, Liu Q, et al. (2010) SiO(2) nanoparticles induce global genomic hypomethylation in HaCaT cells. Biochem Biophys Res Commun 397: 397-400.

92. Khuda-Bukhsh AR, Bhattacharyya SS, Paul S, Dutta S, Boujedaini N, et al (2011) Modulation of Signal Proteins: A Plausible Mechanism to Explain How a Potentized Drug Secale Cor 30C Diluted beyond Avogadro's Limit Combats Skin Papilloma in Mice. Evid Based Complement Alternat Med 2011: 286320.

93. Farkas IJ, Korcsmáros T, Kovács IA, Mihalik Á, Palotai R, et al. (2011) Networkbased tools for the identification of novel drug targets. Sci Signal 4: pt3.

94. Soti C, Pál C, Papp B, Csermely P (2005) Molecular chaperones as regulatory elements of cellular networks. Curr Opin Cell Biol 17: 210-215.

95. Vasquez A, Dobrin R, Sergi D, Eckmann JP, Oltvai ZN, et al. (2004) The topological relationship between the large-scale attributes and local interaction patterns of complex networks. Proceedings of the National Academy of Sciences of the United States of America 101: 17940-17945.

96. Bar-Yam Y, Epstein IR (2004) Response of complex networks to stimuli. Proc Natl Acad Sci U S A 101: 4341-4345.

97. Milisav I, Poljsak B, Suput D (2012) Adaptive response, evidence of crossresistance and its potential clinical use. Int J Mol Sci 13: 10771-10806.

98. Vaiserman AM (2010) Hormesis, adaptive epigenetic reorganization, and implications for human health and longevity. Dose Response 8: 16-21.

99. Van Wijk R, Wiegant FA (2010) Postconditioning hormesis and the homeopathic Similia principle: molecular aspects. Hum Exp Toxicol 29: 561-565.

100. Wiegant FA, Prins HA, Van Wijk R (2011) Postconditioning hormesis put in perspective: an overview of experimental and clinical studies. Dose Response 9: 209-224.

101. Wiegant FA, Spieker N, van Wijk R (1998) Stressor-specific enhancement of hsp induction by low doses of stressors in conditions of self- and crosssensitization. Toxicology 127: 107-119.

102. Kauffman S (1995) At Home in the Universe. The Search for the Laws of SelfOrganization and Complexity. Oxford University Press, New York.

103. Calabrese EJ, Mattson MP (2011) Hormesis provides a generalized quantitative estimate of biological plasticity. J Cell Commun Signal 5: 25-38.

104.Stark M (2012) The sandpile model: optimal stress and hormesis. Dose Response 10: 66-74
105. Iavicoli I, Calabrese EJ, Nascarella MA (2010) Exposure to nanoparticles and hormesis. Dose Response 8: 501-517.

106.Ahn S, Rubchinsky LL, Lapish CC (2013) Dynamical Reorganization of Synchronous Activity Patterns in Prefrontal Cortex-Hippocampus Networks During Behavioral Sensitization. Cereb Cortex.

107. Tan A, De La Peña H, Seifalian AM (2010) The application of exosomes as a nanoscale cancer vaccine. Int J Nanomedicine 5: 889-900.

108. Banerji P, Banerji P (2013) The Banerji Protocols: A New Method of Treatment with Homeopathic Medicine. Prasanta Banerji, Kolkata, India.

109.Banerji P, Campbell DR, Banerji $P$ (2008) Cancer patients treated with the Banerji protocols utilising homoeopathic medicine: a Best Case Series Program of the National Cancer Institute USA. Oncol Rep 20: 69-74.

110. Frenkel M, Mishra BM, Sen S, Yang P, Pawlus A, et al. (2010) Cytotoxic effects of ultra-diluted remedies on breast cancer cells. Int J Oncol 36: 395-403.

111. Howerter A, Hollenstein T, Boon H, Niemeyer K, Brule D (2012) State-space grid analysis: applications for clinical whole systems complementary and alternative medicine research. Forsch Komplementmed 19 Suppl 1: 30-35.

112. Schiff SJ, Jerger K, Duong DH, Chang T, Spano ML, et al. (1994) Controlling chaos in the brain. Nature 370: 615-620.

113. Garfinkel A, Spano ML, Ditto WL, Weiss JN (1992) Controlling cardiac chaos. Science 257: 1230-1235.

114. Costa M, Goldberger AL, Peng CK (2005) Multiscale entropy analysis of biological signals. Phys Rev E Stat Nonlin Soft Matter Phys 71: 021906.

115. Goldberger AL (1996) Non-linear dynamics for clinicians: chaos theory, fractals, and complexity at the bedside. Lancet 347: 1312-1314.

116. Goldberger AL, Amaral LA, Hausdorff JM, Ivanov PCh, Peng CK, et al. (2002) Fractal dynamics in physiology: alterations with disease and aging. Proc Natl Acad Sci U S A 99 Suppl 1: 2466-2472.

117. Manor B, Lipsitz LA (2013) Physiologic complexity and aging: Implication for physical function and rehabilitation. Prog Neuropsychopharmacol Biol Psychiatry 45: 287-293

118. Costa M, Goldberger AL, Peng CK (2002) Multiscale entropy analysis of complex physiologic time series. Phys Rev Lett 89: 068102.

119. Calabrese EJ, Jonas WB (2010) Homeopathy: clarifying its relationship to hormesis. Hum Exp Toxicol 29: 531-536.

120. Torres JL, Ruiz MAG (1996) Stochastic resonance and the homeopathic effect. British Homoeopathic Journal 85: 134-140.

121.Sugarman J, Tsai S, Santamaria P, Khadra A (2013) Quantifying the importance of pMHC valency, total pMHC dose and frequency on nanoparticle therapeutic efficacy. Immunol Cell Biol 91: 350-359.

122. Calabrese EJ, lavicoli I, Calabrese V (2013) Hormesis: its impact on medicine and health. Hum Exp Toxicol 32: 120-152.

123. Nascarella MA, Calabrese EJ (2012) A method to evaluate hormesis in nanoparticle dose-responses. Dose Response 10: 344-354.

124. Van Wijk R, Wiegant FA (2011) Postconditioning hormesis and the similia principle. Front Biosci (Elite Ed) 3: 1128-1138

125. Soti C, Csermely P (2007) Aging cellular networks: chaperones as major participants. Exp Gerontol 42: 113-119.

126. Malarczyk E, Pazdzioch-Czochra M, Graz M, Kochmanska-Rdest J, Jarosz Wilkolazka A (2011) Nonlinear changes in the activity of the oxygen-dependent demethylase system in Rhodococcus erythropolis cells in the presence of low and very low doses of formaldehyde. Nonlinear Biomed Phys 5: 9.

127.Sorg BA, Bailie TM, Tschirgi ML, Li N, Wu WR (2001) Exposure to repeated low-level formaldehyde in rats increases basal corticosterone levels and enhances the corticosterone response to subsequent formaldehyde. Brain Res 898: 314-320.

128. Barr AM, Hofmann CE, Weinberg J, Phillips AG (2002) Exposure to repeated intermittent d-amphetamine induces sensitization of HPA axis to a subsequent stressor. Neuropsychopharmacology 26: 286-294.

129. Deroche V, Marinelli M, Maccari S, Le Moal M, Simon H, et al. (1995) Stressinduced sensitization and glucocorticoids. I. Sensitization of dopamine- 
Citation: Bell IR, Sarter B, Koithan M, Standish LJ, Banerji P, et al. (2013) Nonlinear Response Amplification Mechanisms for Low Doses of Natural Product Nanomedicines: Dynamical Interactions with the Recipient Complex Adaptive System. J Nanomed Nanotechol 4: 179. doi:10.4172/2157-7439.1000179

dependent locomotor effects of amphetamine and morphine depends on stress-induced corticosterone secretion. J Neurosci 15: 7181-7188.

130. Antelman SM, Caggiula AR, Kocan D, Knopf S, Meyer D, et al. (1991) One experience with 'lower' or 'higher' intensity stressors, respectively enhances or diminishes responsiveness to haloperidol weeks later: implications for understanding drug variability. Brain Res 566: 276-283.

131. Antelman SM, Levine J, Gershon S (2000) Time-dependent sensitization: the odyssey of a scientific heresy from the laboratory to the door of the clinic. Mo Psychiatry 5: 350-356.

132. Antelman SM, Caggiula AR (1996) Oscillation follows drug sensitization: implications. Crit Rev Neurobiol 10: 101-117.

133. Bell IR, Lewis DA 2nd, Lewis SE, Schwartz GE, Brooks AJ, et al. (2004) EEG alpha sensitization in individualized homeopathic treatment of fibromyalgia. Int J Neurosci 114: 1195-1220.

134. Bell IR, Brooks AJ, Howerter A, Jackson N, Schwartz GE (2013) Acute electroencephalographic effects from repeated olfactory administration of homeopathic remedies in individuals with self-reported chemical sensitivity. Altern Ther Health Med.19: 46-57.

135. McDonnell MD, Abbott D (2009) What is stochastic resonance? Definitions misconceptions, debates, and its relevance to biology. PLoS Comput Biol 5: e1000348.

136. Poccia N, Ansuini A, Bianconi A (2011) Far from equilibrium percolation, stochastic and shape resonances in the physics of life. Int J Mol Sci 12: 68106833

137. Moss F, Ward LM, Sannita WG (2004) Stochastic resonance and sensory information processing: a tutorial and review of application. Clin Neurophysiol 115: $267-281$

138. Joshi A (2008) Stochastic resonance in a double quantum dot system. Phys Rev E Stat Nonlin Soft Matter Phys 77: 020104.

139. Lee I, Liu X, Chongwu Z, Kosko B (2006) Noise-Enhanced Detection of Subthreshold Signals With Carbon Nanotubes. IEEE Transactions on Nanotechnology 5: 613-627.

140. Gilden DL, Thornton T, Mallon MW (1995) 1/f noise in human cognition. Science 267: 1837-1839.

141. Guerra DN, Dunn T, Mohanty $P$ (2009) Signal amplification by $1 / f$ noise in silicon-based nanomechanical resonators. Nano Lett 9: 3096-3099.

142. Cervera J, Manzanares JA, Mafé S (2010) Reliable signal processing using parallel arrays of non-identical nanostructures and stochastic resonance. Nanoscale 2: 1033-1038.

143. Cervera J, Manzanares JA, Mafé S (2011) Sub-threshold signal processing in arrays of non-identical nanostructures. Nanotechnology 22: 435201.

144.Bell IR, Lewis DA, Schwartz GE, Lewis SE, Caspi O, et al. (2004) Electroencephalographic cordance patterns distinguish exceptional clinical responders with fibromyalgia to individualized homeopathic medicines. J Altern Complement Med 10: 285-299.

145. Gądek-Michalska A, Tadeusz J, Rachwalska P, Spyrka J, Bugajski J. (2012) Brain nitric oxide synthases in the interleukin-1ß-induced activation of hypothalamic-pituitary-adrenal axis. Pharmacol Rep 64: 1455-1465.

146. Costa M, Priplata AA, Lipsitz LA, Wu Z, Huang NE, et al. (2007) Noise and poise: Enhancement of postural complexity in the elderly with a stochasticresonance-based therapy. Europhys Lett 77: 68008.

147. Walach H (2003) Entanglement model of homeopathy as an example of generalized entanglement predicted by weak quantum theory. Forsch Komplementarmed Klass Naturheilkd 10: 192-200.

148. Beauvais F (2013) A quantum-like model of homeopathy clinical trials: importance of in situ randomization and unblinding. Homeopathy 102: 106113.

149. Milgrom LR (2007) Conspicuous by its absence: the Memory of Water, macroentanglement, and the possibility of homeopathy. Homeopathy 96: 209-219.

150.Sangghaleh F, Bruhn B, Schmidt T, Linnros J (2013) Exciton lifetime measurements on single silicon quantum dots. Nanotechnology 24: 225204

151. Luther JM, Jain PK, Ewers T, Alivisatos AP (2011) Localized surface plasmon resonances arising from free carriers in doped quantum dots. Nat Mater 10: 361-366.
152. Hennessy K, Badolato A, Winger M, Gerace D, Atatüre M, et al. (2007) Quantum nature of a strongly coupled single quantum dot-cavity system. Nature 445: 896-899.

153. Reimann P, Hanggi P (1998) Quantum features of Brownian motors and stochastic resonance. Chaos 8: 629-642.

154. Bellavite P, Marzotto M, Chirumbolo S, Conforti A (2011) Advances in homeopathy and immunology: a review of clinical research. Front Biosci (Schol Ed) 3: 1363-1389.

155. Bracho G, Varela E, Fernández R, Ordaz B, Marzoa N, et al. (2010) Largescale application of highly-diluted bacteria for Leptospirosis epidemic control. Homeopathy 99: 156-166.

156. Höppener C, Lapin ZJ, Bharadwaj P, Novotny L (2012) Self-similar goldnanoparticle antennas for a cascaded enhancement of the optical field. Phys Rev Lett 109: 017402

157. Timmerman D, Gregorkiewicz T (2012) Power-dependent spectral shift of photoluminescence from ensembles of silicon nanocrystals. Nanoscale Res Lett 7: 389

158. Lukianova-Hleb EY, Belyanin A, Kashinath S, Wu X, Lapotko DO (2012) Plasmonic nanobubble-enhanced endosomal escape processes for selective and guided intracellular delivery of chemotherapy to drug-resistant cancer cells. Biomaterials 33: 1821-1826.

159. Lukianova-Hleb EY, Oginsky AO, Shenefelt DL, Drezek RA, Hafner JH, et al. (2011) Rainbow Plasmonic Nanobubbles: Synergistic Activation of Gold Nanoparticle Clusters. J Nanomed Nanotechnol 2: 1-8.

160. Lee SE, Lee LP (2010) Biomolecular plasmonics for quantitative biology and nanomedicine. Curr Opin Biotechnol 21: 489-497.

161.Lee IY, Liu X, Kosko B, Zhou C (2003) Nanosignal Processing:? Stochastic Resonance in Carbon Nanotubes That Detect Subthreshold Signals. Nano Lett 3: 1683-1686.

162. Al-Sadoon MK, Abdel-Maksoud MA, Rabah DM, Badr G (2012) Induction of apoptosis and growth arrest in human breast carcinoma cells by a snake (Walterinnesia aegyptia) venom combined with silica nanoparticles: crosstalk between $\mathrm{Bcl} 2$ and caspase 3. Cell Physiol Biochem 30: 653-665.

163. Sirleto L, Ferrara MA, Nikitin T, Novikov S, Khriachtchev L (2012) Giant Raman gain in silicon nanocrystals. Nat Commun 3: 1220

164. Rowe DJ, Jeong JS, Mkhoyan KA, Kortshagen UR (2013) Phosphorusdoped silicon nanocrystals exhibiting mid-infrared localized surface plasmon resonance. Nano Lett 13: 1317-1322.

165. Montagnier L, Aïssa J, Ferris S, Montagnier JL, Lavallée C (2009) Electromagnetic signals are produced by aqueous nanostructures derived from bacterial DNA sequences. Interdiscip Sci 1: 81-90.

166. Dung MX, Choi JK, Jeong HD (2013) Newly synthesized silicon quantum dotpolystyrene nanocomposite having thermally robust positive charge trapping. ACS Appl Mater Interfaces 5: 2400-2409.

167. Gupta A, Wiggers H (2011) Freestanding silicon quantum dots: origin of red and blue luminescence. Nanotechnology 22: 055707.

168. Molski M (2010) Quasi-quantum phenomena: the key to understanding homeopathy. Homeopathy 99: 104-112.

169. McKibbin SR, Scappucci G, Pok W, Simmons MY (2013) Epitaxial top-gated atomic-scale silicon wire in a three-dimensional architecture. Nanotechnology 24: 045303.

170. Relaix S, Leheny RL, Reven L, Sutton M (2011) Memory effect in composites of liquid crystal and silica aerosil. Phys Rev E Stat Nonlin Soft Matter Phys 84: 061705.

171.Patra HK, Dasgupta AK (2012) Cancer cell response to nanoparticles: criticality and optimality. Nanomedicine 8: 842-852.

172. Pathak S, Multani AS, Banerji P, Banerji P (2003) Ruta 6 selectively induces cell death in brain cancer cells but proliferation in normal peripheral blood lymphocytes: A novel treatment for human brain cancer. Int J Oncol 23: 975982.

173. Fadlalla K, Watson A, Yehualaeshet T, Turner T, Samuel T (2011) Ruta graveolens extract induces DNA damage pathways and blocks Akt activation to inhibit cancer cell proliferation and survival. Anticancer Res 31: 233-241.

174. Varamini P, Soltani M, Ghaderi A (2009) Cell cycle analysis and cytotoxic 
Citation: Bell IR, Sarter B, Koithan M, Standish LJ, Banerji P, et al. (2013) Nonlinear Response Amplification Mechanisms for Low Doses of Natural Product Nanomedicines: Dynamical Interactions with the Recipient Complex Adaptive System. J Nanomed Nanotechol 4: 179. doi:10.4172/2157-7439.1000179

potential of Ruta graveolens against human tumor cell lines. Neoplasma 56: 490-493.

175. Mauludin R, Müller RH, Keck CM (2009) Development of an oral rutin nanocrystal formulation. Int J Pharm 370: 202-209.

176. Chu SH, Feng DF, Ma YB, Li ZQ (2012) Hydroxyapatite nanoparticles inhibit the growth of human glioma cells in vitro and in vivo. Int $\mathrm{J}$ Nanomedicine 7 : 3659-3666.

177.Spin-Neto R, Belluci MM, Sakakura CE, Scaf G, Pepato MT, et al. (2010) Homeopathic Symphytum officinale increases removal torque and radiographic bone density around titanium implants in rats. Homeopathy 99: 249-254.

178.Badr G, Al-Sadoon MK, Rabah DM, Sayed D (2013) Snake (Walterinnesia aegyptia) venom-loaded silica nanoparticles induce apoptosis and growth arrest in human prostate cancer cells. Apoptosis 18: 300-314.

179. Sayed D, Al-Sadoon MK, Badr G (2012) Silica nanoparticles sensitize human multiple myeloma cells to snake (Walterinnesia aegyptia) venom-induced apoptosis and growth arrest. Oxid Med Cell Longev 2012: 386286.

180. Belton DJ, Deschaume O, Perry CC (2012) An overview of the fundamentals of the chemistry of silica with relevance to biosilicification and technological advances. FEBS J 279: 1710-1720.
181. Barik TK, Sahu B, Swain V (2008) Nanosilica-from medicine to pest control Parasitol Res 103: 253-258.

182. Müller WE, Wang X (2012) Silicatein: from chemical through enzymatic silica formation, to synthesis of biomimetic nanomaterials. FEBS J 279: 1709.

183. Karig DK, Siuti P, Dar RD, Retterer ST, Doktycz MJ, et al. (2011) Model for biological communication in a nanofabricated cell-mimic driven by stochastic resonance. Nano Commun Netw 2: 39-49.

184. Hahnemann S (1843) Organon of the Medical Art. 6th ed.; O'Reilly WB, Decker S, editors. Redmond, WA: Birdcage Books.

185. Baumgartner S (2009) The State of Basic Research on Homeopathy. In: Wit $\mathrm{C}$, Albrecht H, editors. New Directions in Homeopathy Research. Essen, Germany, KVC Verlag Pp: 107-130.

186. Endler P, Thieves K, Reich C, Matthiessen P, Bonamin L, et al. (2010) Repetitions of fundamental research models for homeopathically prepared dilutions beyond 10(-23): a bibliometric study. Homeopathy 99: 25-36.

187. Calabrese EJ (2008) Hormesis and medicine. Br J Clin Pharmacol 66: 594617. 